\title{
Prosthetic Rehabilitation of Deeply Placed Implant
}

\author{
Preetica Sharma ${ }^{1}$ Tarun Kalra ${ }^{1} \quad$ Manjit Kumar $^{1} \quad$ Ajay Bansal $^{1} \quad$ Shefali Singh Malik ${ }^{1}$ \\ ${ }^{1}$ Department of Prosthodontics, Bhojia Dental College and Hospital, \\ Solan, Himachal Pradesh, India \\ Address for correspondence Manjit Kumar, MDS, Department of \\ Prosthodontics, Bhojia Dental College and Hospital, Solan, Himachal \\ Pradesh 173205, India (e-mail: manjitkiran@yahoo.co.in).
}

Dent J Adv Stud:2021;9:48-50

\begin{abstract}
Keywords

- dental implant

- malposition

- transmucosal

abutment

Fixed prosthetic option is the most accepted treatment desired by the patient in modern times. Malpositioned implant presents a challenge, especially during prosthetic phase. The prosthetic achievement of various complex cases can be done by following appropriate procedure; one of which has been discussed in this report. The use of transmucosal abutment with castable abutment is successful treatment option for complex malposed single dental implant.
\end{abstract}

\section{Introduction}

In modern dental practice, the prosthodontists aim for better comfort, function, contour, aesthetics, speech, and health of the stomatognathic system. ${ }^{1}$ More stress is given on the replacement of first molars, which is the key stone dental arches and become caries as it is the first tooth to erupt in the oral cavity.

For completely and partially edentulous patients, implant supported restoration is the choice of treatment. ${ }^{2}$ In literature for the replacement single missing tooth, $97 \%$ success rate for 5-year follow-up is there. ${ }^{3}$

Osseo integration and loading protocol are the main parameters in success of implants. Even after due treatment planning, complication in the implant placement do occure. ${ }^{4}$

During treatment planning for restorative phase, nonoptimal implant position is seen in three geometric planes, that is, facial palatal angulation and depth and position of the implant. ${ }^{5}$ The location, length, and angulation are the paramount factors for optimal implant supported prosthesis.

Even after proper osseointegration, there is a big challenge to restore it if its location is not correct, which leads to failure and affects the longevity of the prosthesis. To restore deeply positioned dental implant sometimes becomes challenge to prosthodontists and dental laboratory technicians. ${ }^{6}$
In the present case report, prosthetic rehabilitation of deeply seated implant is discussed.

\section{Case Report}

A 24-year-old female patient was referred to the department of prosthodontics for prosthetic rehabilitation of a deeply placed implant in the mandibular right first molar area (-Fig. 1). Clinically and radiographically implant was nicely healed and well osseointegrated.

The prosthetic rehabilitation with standard abutment was difficult in this case as the implant was deeply seated.

After prescribed healing period for osseointegration, second stage surgery was performed to expose the implant with an incision in the first molar area and healing abutment was placed on the exposed implant for initial soft tissue healing (-Fig. 2). After 2 weeks, the healing abutment was removed and a healthy soft tissue cuff was formed around implant.

In this case, an open tray impression technique was used. An impression post was screwed to the implant (-Fig. 3). Open custom tray was fabricated. Base and catalyst paste of condensation silicone Zetaplus Zhermack (Italy) was mixed and loaded into a custom tray, and light body was injected through syringe around impression transfer coping and some
DOI https://doi.org/

10.1055/s-0041-1723870

ISSN 2321-1482.
(C2021. Bhojia Dental College and Hospital affiliated to Himachal Pradesh University.

This is an open access article published by Thieme under the terms of the Creative Commons Attribution-NonDerivative-NonCommercial-License, permitting copying and reproduction so long as the original work is given appropriate credit. Contents may not be used for commercial purposes, or adapted, remixed, transformed or built upon. (https://creativecommons.org/licenses/by-nc-nd/4.0/).

Thieme Medical and Scientific Publishers Pvt. Ltd. A-12, 2nd Floor, Sector 2, Noida-201301 UP, India 


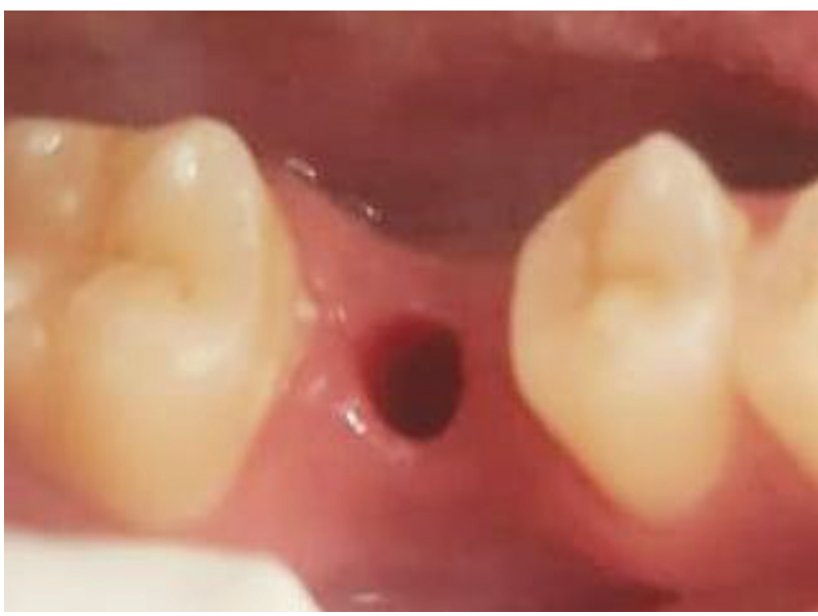

Fig. 1 Deeply placed dental implant.

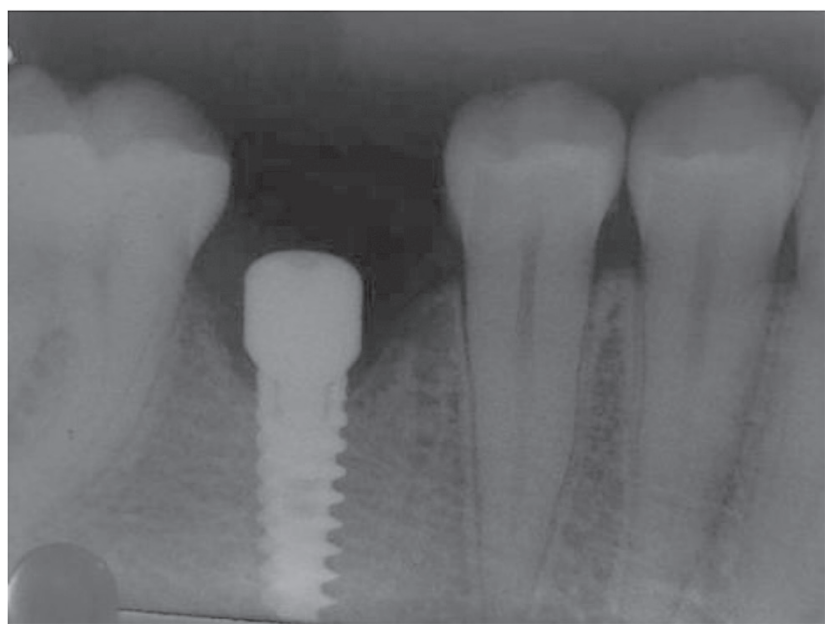

Fig. 2 Intraoral periapical radiograph confirming deeply placed implant.

amount of light body was placed on the loaded material in the region, which coincided with the implant and impression was made in single step. Impression was removed from oral cavity and checked for surface details (-Fig. 4). An implant analog was screwed to the impression post and tightly secured at its place to avoid any movement during this procedure.

Gingival mimic was created around the gingival portion of the abutment with gingifast Zhermack (Italy). The impression was poured with class IV gypsum product (die stone Kalabai Mumbai). For correction of deeply seated implant, a castable abutment was used in this case (-Fig. 5). Finished castable abutment was connected to the substructure as transmucosal abutment. An intraperiapical radiograph was taken to check the proper seating of the components. A screw retained prosthesis was constructed over the castable abutment (-Fig. 6).

\section{Discussion}

Ultimate long-term goal to successful implant treatment can be achieved through well organized and thorough treatment plan, which ultimately leads to patient's satisfaction. Proper diagnosis and treatment planning to diagnose any

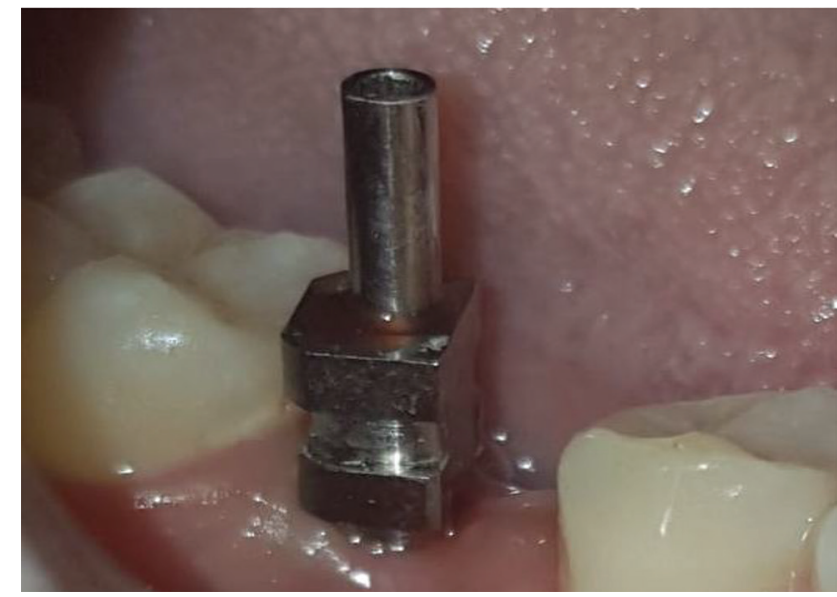

Fig. 3 Impression post connected to implant fixture.

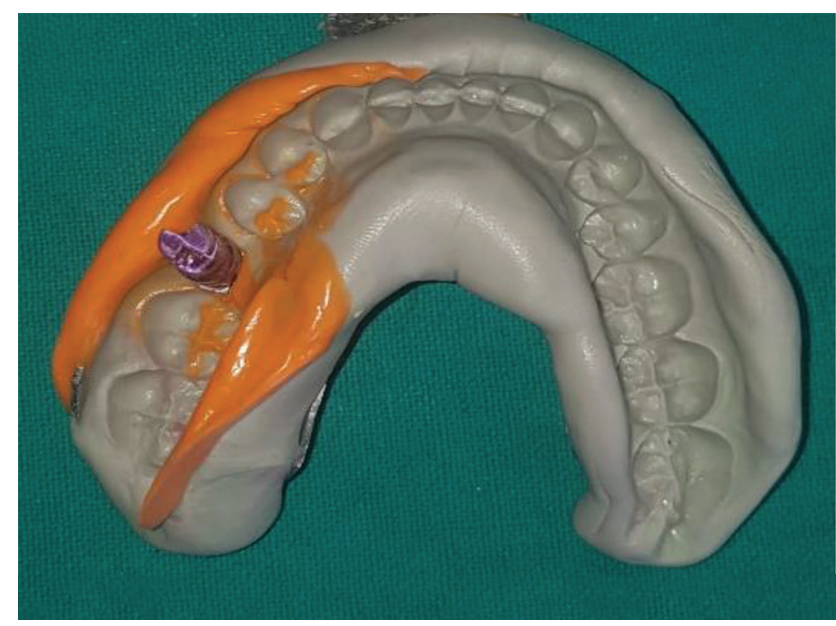

Fig. 4 Final impression.

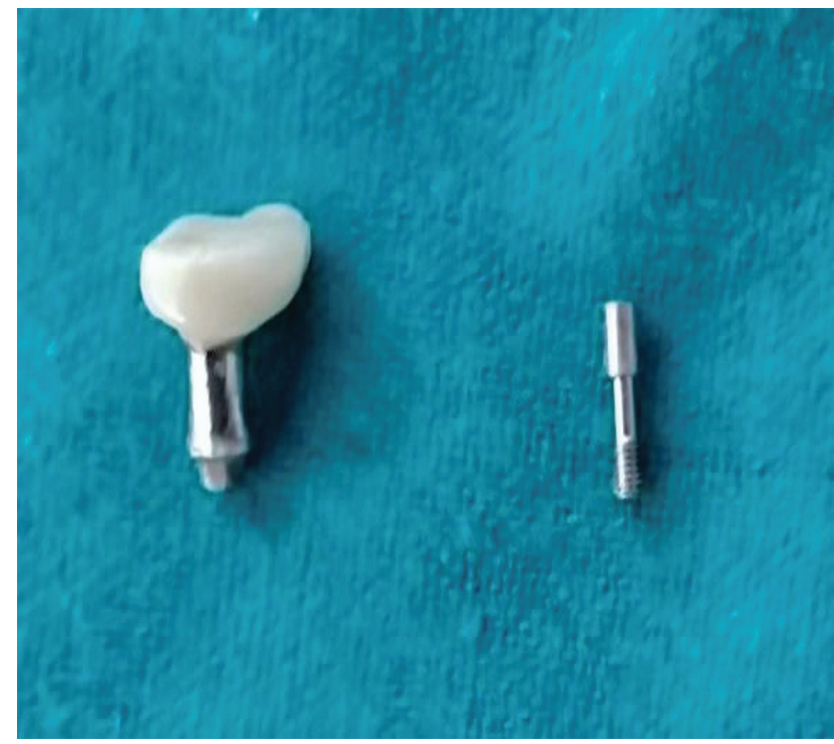

Fig. 5 Castable abutment with screw retained prosthesis.

complication beforehand is utmost important in implant prosthodontics. Absolute and relative risk factors jeopardized the success of implant predictability. ${ }^{7}$ 


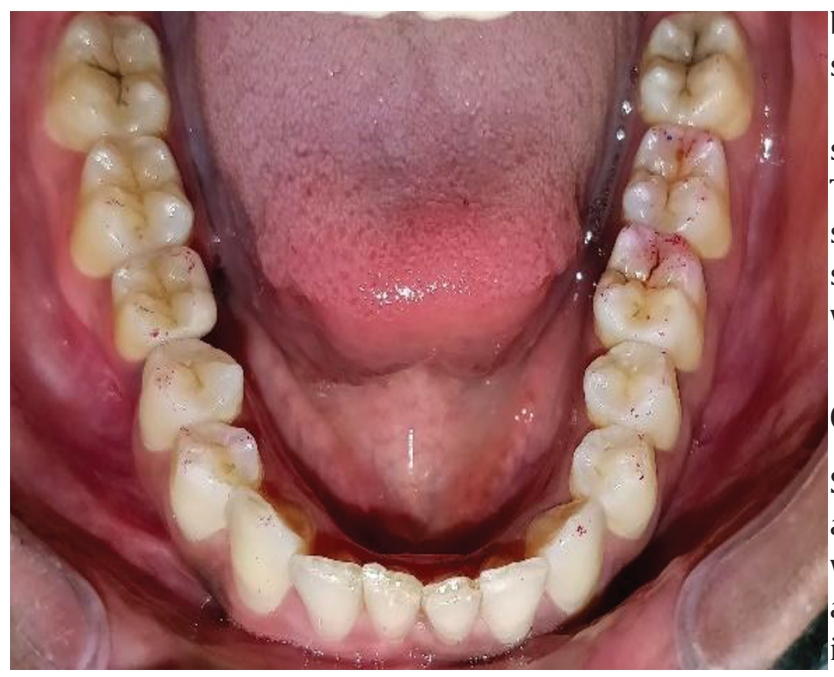

Fig. 6 Final prosthesis.

Implant supported restorations have various complications that could be due to improper treatment planning; case selection; inadequate communication between the patient, the surgeon, the prosthodontist and laboratory personnel, etc. Improper surgical placement of dental implants has been considered most common clinical complication.

Mostly prosthetic complications in implant prosthodontics are due to poor treatment planning and failure to use $\mathrm{e}^{\mathrm{Re}}$ surgical stent for placement of implants. Prosthodontist has to face a challenging situation while managing the prosthetic phase of malposed implant. ${ }^{8}$

Proper treatment protocol should be followed up. Use of surgical stent provide three dimensional (buccolingual, mesiodistal, and occlusoapical) view of the insertion of implant. Prosthodontist should follow smooth transition from surgical phase to prosthetic phase of the prosthodontic rehabilitation.

For three dimensional planning of implant insertion, radiograph with study cast are very important tools. To overcome complications in implant placement, many techniques have been used like angulated abutments, castable abutments, or in severe cases removable prothesis. ${ }^{8}$ Longterm success of implants and implant-supported prosthesis depends on the precise fit between dental implant and the superstructure. ${ }^{9}$ According to Cavallaro and Greenstein, the complications arose due to improper selection of abutment resulting in aesthetic, and peri-implant complications can be corrected by using appropriate prosthetic component design to restore the health of soft tissue surrounding malpositioned implant. Abutment scan affect the implant stress and strain distribution, changing the forces transmission to the adjacent bone. ${ }^{10}$

When the implant is deeply seated with overlying thick soft tissue, height of the healing abutment can be increased by laser welding. This will also provide proper healing of the soft tissue, comfort, and convenience to the patient. ${ }^{11}$

The deeply seated implant is one of the most challenging situations for the prosthodontist for prosthetic rehabilitation. To overcome this situation in this case report, a transmucosal abutment was used that provide the marginal soft tissue seal (cuff) to surround the implant. Screw retained prosthesis was given to the patient.

\section{Conclusion}

Serious complications in implant placement are not common and these situations can be avoided. Presurgical radiographs, wax ups, and detail diagnosis and treatment planning can avoid these problems. With the use of an extension of the impression coping implant, depth effect could be compensated. Proper training for implantology should be done for advance surgical and prosthetic rehabilitation of cases requiring implant as a choice of treatment.

\section{Funding}

None.

\section{Conflict of Interest}

None declared.

\section{References}

1 Dewan S, Khullar A, Sehgal M, Arora A. Implant failures: a broader perspective. J Dent Implant 2015;5(1):53-59

2 Misch C, Dental Implant Prosthetics. 2nd ed. USA:Elsevier Mosy; 2014: 214-216

3 Zitzmann NU, Arnold D, Ball J, Brusco D, Triaca A, Verna C. Treatment strategies for infraoccluded dental implants. J Prosthet Dent 2015;113(3):169-174

4 Cavallaro J, Greenstein G, Prosthodontic complications related to non-optimal dental implant placement2010;156-171

5 Chatterjee A, Ragher M, Patil S, Chatterjee D, Dandekeri S, Prabhu V. Prosthetic management of malpositioned implant using custom cast abutment. J Pharm Bioallied Sci 2015;7 (6, Suppl 2) :S740-S745

6 Al-Fahd A, Radi I. Management of complex deeply positioned, severely malaligned dental implant. JIACD 2015;7(9):31-35

7 Misch K, Wang HL. Implant surgery complications: etiology and treatment. Implant Dent 2008;17(2):159-168

8 Chincholikar S, Singh S, Kalavathy N, Kapoor A. Prosthodontic management of malpositioned implants in anterior maxillary region: a case series. IOSRJDMS 2018;17(7):63-71

9 Linkevicius T, Svediene O, Vindasiute E, Linkeviciene L. A technique for making impressions of deeply placed implants. J Prosthet Dent 2011;106(3):204-205

10 de Avila ED, de Molon RS, de Barros-Filho LA, de Andrade MF, Mollo FdeA Jr, de Barros LA. Correction of malpositioned implants through periodontal surgery and prosthetic rehabilitation using angled abutment. Case Rep Dent 2014;2014:702630

11 Yilmaz B, McGlumphy E, Turkyilmaz I. A technique to modify the length of an implant healing abutment. J Oral Implantol 2009;35(4):201-203 